Wright State University

CORE Scholar

10-1-2005

\title{
Traps in AlGaN/GaN/SiC Heterostructures Studied by Deep Level Transient Spectroscopy
}

\author{
Z-Q. Fang \\ David C. Look \\ Wright State University - Main Campus, david.look@wright.edu \\ D. H. Kim
}

I. Adesida

Follow this and additional works at: https://corescholar.libraries.wright.edu/physics

Part of the Physics Commons

\section{Repository Citation}

Fang, Z., Look, D. C., Kim, D. H., \& Adesida, I. (2005). Traps in AlGaN/GaN/SiC Heterostructures Studied by Deep Level Transient Spectroscopy. Applied Physics Letters, 87 (18), 182115.

https://corescholar.libraries.wright.edu/physics/92

This Article is brought to you for free and open access by the Physics at CORE Scholar. It has been accepted for inclusion in Physics Faculty Publications by an authorized administrator of CORE Scholar. For more information, please contact library-corescholar@wright.edu. 


\title{
Traps in AIGaN/GaN /SiC heterostructures studied by deep level transient spectroscopy
}

\author{
Z.-Q. Fang ${ }^{\text {a) }}$ and D. C. Look \\ Semiconductor Research Center, Wright State University, Dayton, Ohio 45435 and Materials and \\ Manufacturing Directorate, Air Force Research Laboratory, Wright-Patterson AFB, Ohio 45433 \\ D. H. Kim and I. Adesida \\ Micro and Nanotechnology Laboratory and Department of Electrical and Computer Engineering, \\ University of Illinois, Urbana, Illinois 61801
}

(Received 3 May 2005; accepted 12 September 2005; published online 28 October 2005)

\begin{abstract}
$\mathrm{AlGaN} / \mathrm{GaN} / \mathrm{SiC}$ Schottky barrier diodes (SBDs), with and without $\mathrm{Si}_{3} \mathrm{~N}_{4}$ passivation, have been characterized by temperature-dependent current-voltage and capacitance-voltage measurements, and deep level transient spectroscopy (DLTS). A dominant trap $A_{1}$, with activation energy of $1.0 \mathrm{eV}$ and apparent capture cross section of $2 \times 10^{-12} \mathrm{~cm}^{2}$, has been observed in both unpassivated and passivated SBDs. Based on the well-known logarithmic dependence of DLTS peak height with filling pulse width for a line-defect related trap, $A_{1}$, which is commonly observed in thin GaN layers grown by various techniques, is believed to be associated with threading dislocations. At high temperatures, the DLTS signal sometimes becomes negative, likely due to an artificial surface-state effect. () 2005 American Institute of Physics. [DOI: 10.1063/1.2126145]
\end{abstract}

Trapping effects in AlGaN/GaN high electron mobility transistors (HEMTs) currently present a major limitation on the power performance at high frequencies. Electrical charge trapped on the surface and/or in the bulk of the heterostructure alters the density of two-dimensional electron gas (2DEG) in the channel and limits the switching characteristics of the device. A number of research efforts have been directed toward identification and elimination of the trapping effects in $\mathrm{AlGaN} / \mathrm{GaN}$ transistors. These studies have utilized several different characterization techniques, including photoionization spectroscopy, ${ }^{1}$ drain leakage-current measurements, ${ }^{2}$ transient drain current measurements at different temperatures, ${ }^{3}$ and current-mode deep level transient spectroscopy (DLTS). ${ }^{4}$ In the present investigation, we have employed capacitance-mode DLTS, using Schottky barrier diodes (SBDs) formed on the AlGaN. One benefit of using capacitance DLTS is that we can then compare the observed traps in the $\mathrm{AlGaN} / \mathrm{GaN}$ structure with commonly observed traps in $\mathrm{GaN}$ alone.

The AlGaN/GaN bilayer was grown by metalorganic chemical-vapor deposition (CVD) on an $n$-type $4 \mathrm{H}-\mathrm{SiC}$ substrate. It consisted of an AlN buffer layer, an unintentionally doped GaN layer $(\sim 1 \mu \mathrm{m}$ thick), and an unintentionally doped $\mathrm{AlGaN}$ layer (200 $\AA$ thick), with an $\mathrm{Al}$ mole fraction of $30 \%$. Schottky dots of $250 \mu \mathrm{m}$, and large-area Ohmic contacts surrounding the dots, were fabricated on the surface using $\mathrm{Ni} / \mathrm{Au}$ and $\mathrm{Ti} / \mathrm{Al} / \mathrm{Mo} / \mathrm{Au}$ metallizations, respectively. To study the effects of passivation, SBDs with and without $\mathrm{Si}_{3} \mathrm{~N}_{4}$ passivation were fabricated. In the passivated SBDs, $\mathrm{Si}_{3} \mathrm{~N}_{4}$ (100 nm thick) was deposited by plasma-enhanced $\mathrm{CVD}$ at $300{ }^{\circ} \mathrm{C}$. For probing, contact holes were etched in a $\mathrm{CF}_{4}$ gas using a Freon reactive ion etching system. The Schottky/Ohmic spacing was $12.5 \mu \mathrm{m}$ for both of the unpassivated and passivated SBDs. A Bio-Rad DL4600 spectrometer with a $100 \mathrm{mV}, 1 \mathrm{MHz}$ test signal, and a Keithley 617 programmable electrometer were used to obtain $I-V$, capacitance-voltage $(C-V)$, and DLTS data. The carrier con-

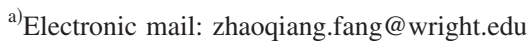

centration as a function of depth or bias was derived from the $C$ - $V$ data. To profile the traps within the $\mathrm{GaN}$ and even AlGaN regions, the reverse bias $\left(V_{b}\right)$ and filling pulse height $\left(V_{f}\right)$ were varied. Also, to determine whether or not a trap is associated with point defects (such as substitutional impurities) or extended defects (such as threading dislocations), the DLTS spectra were measured as a function of filling pulse width $\left(W_{f}\right)$. Finally, the usual trap parameters (activation energy $E_{T}$ and apparent capture cross section $\sigma_{n}$ ) were determined from an Arrhenius analysis of the DLTS peak positions as a function of rate window $\left(e_{n}\right)$, typically varied between 0.8 and $50 \mathrm{~s}^{-1}$.

Typical temperature-dependent $I-V$ characteristics for an unpassivated SBD are shown in Fig. 1. From the figure, we see that: (i) the reverse currents are not strongly temperature dependent, indicating the dominancy of tunneling conduction; (ii) the reverse currents at $\left|V_{b}\right|>3 \mathrm{~V}$ are quite low (below $1 \times 10^{-5} \mathrm{~A}$ at $400 \mathrm{~K}$ ) and nearly constant, due to complete depletion of the 2DEG (compare Fig. 2); and (iii) the forward currents show a kink structure, which may be due to tunneling currents at low biases. Many models have been

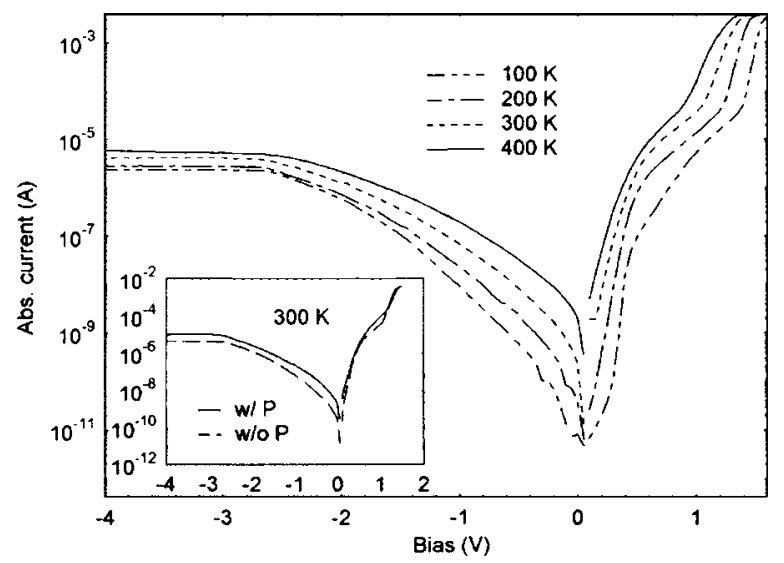

FIG. 1. I- $V$ characteristics, measured at different temperatures, for an unpassivated SBD (inset shows a comparison of $300 \mathrm{~K} \mathrm{I-V}$ for the unpassivated and passivated SBDs). 


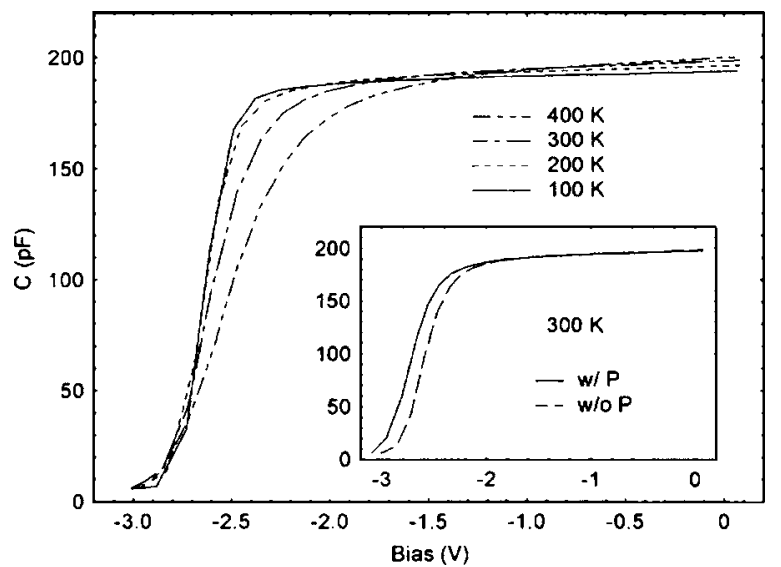

FIG. 2. $C-V$ characteristics, measured at different temperatures, for the unpassivated SBD (inset shows a comparison of $300 \mathrm{~K} C$ - $V$ for the unpassivated and passivated SBDs).

proposed to explain the excess leakage currents in SBDs on $\mathrm{GaN}$ or $\mathrm{AlGaN} / \mathrm{GaN}$, including the thin surface barrier model ${ }^{5}$ and the field-emission/trap-assisted tunneling model. ${ }^{6}$ However, a detailed analysis of the $I-V$ curves is beyond the scope of this paper. Typical $C-V$ characteristics at different temperatures for the unpassivated SBD are presented in Fig. 2. From the figure, we find that: (i) the capacitance is flat at low reverse biases, due to only small changes in the 2DEG peak depth $d(C \propto 1 / d)$, and then decreases rapidly, depending on temperature, as the 2DEG is pinched off; (ii) as $\left|V_{b}\right|$ further increases, say to $V_{b}=-3.0 \mathrm{~V}$, the capacitance reduces to a constant parasitic value, independent of temperature; and (iii) the pinch-off process at $400 \mathrm{~K}$ is more gradual than that at $100 \mathrm{~K}$, which could be partly related to trapping effects at high temperatures (as discussed below). Typical $I-V$ and $C-V$ characteristics for a passivated SBD are similar to those of the unpassivated SBD. A comparison of the $300 \mathrm{~K} I-V$ and $C-V$ curves for the passivated and unpassivated SBDs are presented in the insets of Figs. 1 and 2, respectively. As compared to the case of the SBD without passivation $(\mathrm{w} / \mathrm{o} P$ ), the SBD with passivation $(\mathrm{w} / P$ ) shows a slight increase in both reverse and forward currents, and in pinch-off voltage as well. Carrier concentration and depth, as a function of bias for both SBDs (i.e., w/o and w/P), are pictured in Fig. 3 and its inset, where no significant difference in 2 DEG concentration can be observed as a function of passivation, except in the pinch-off region. Carrier profiles

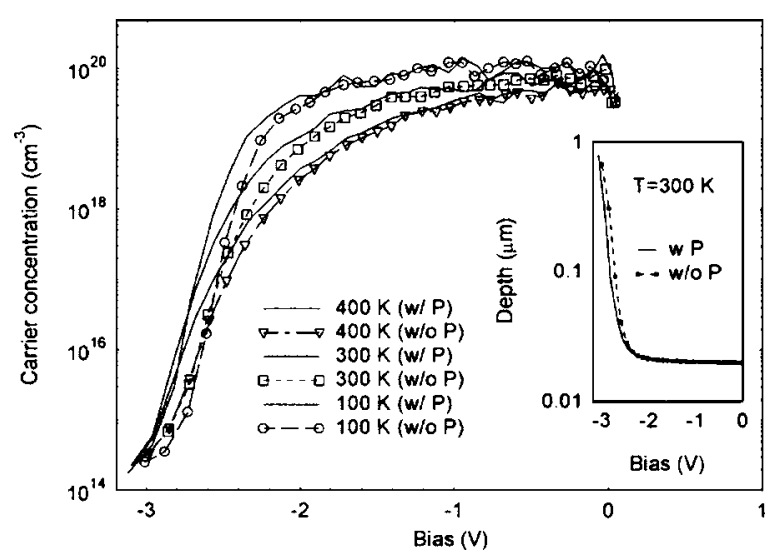

FIG. 3. Carrier concentration vs bias, measured at different temperatures, for both unpassivated and passivated SBDs (inset shows $300 \mathrm{~K}$ depth vs bias for both SBDs).

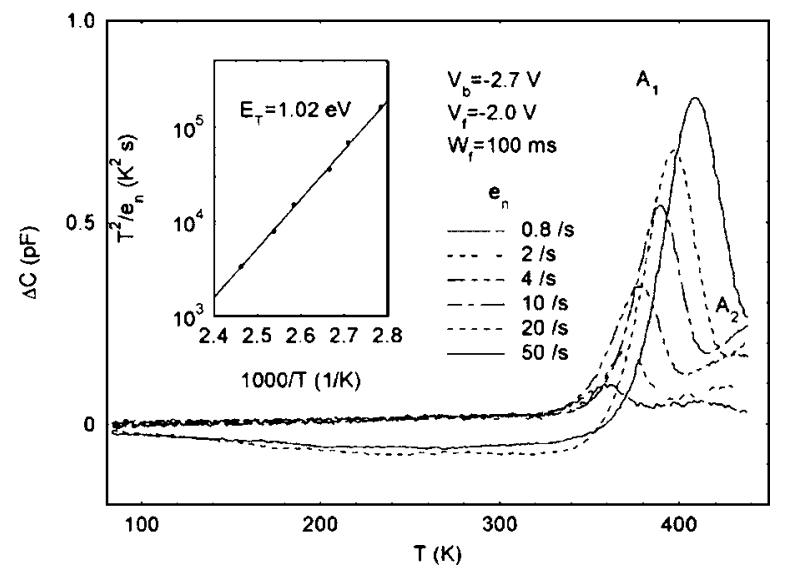

FIG. 4. DLTS spectra measured as a function of rate window for the unpassivated SBD (inset shows Arrhenius plot for trap $A_{1}$ ).

(not shown here) show a 2DEG depth of $0.2 \mathrm{~nm}$ and a $2 \mathrm{DEG}$ peak density of $8 \times 10^{19} \mathrm{~cm}^{-3}$ at $300 \mathrm{~K}$ for both SBDs.

DLTS spectra as a function of rate window measured in the pinch-off region (by setting $V_{b}=-2.7 \mathrm{~V}$ and $V_{f}=-2.0 \mathrm{~V}$ ) are presented in Fig. 4. The dominant trap is clearly $A_{1}$ and $\operatorname{trap} A_{2}$ also appears. From an Arrhenius analysis (see inset of the figure), the activation energy and apparent capture cross section for trap $A_{1}$ were determined to be $1.02 \mathrm{eV}$ and $2 \times 10^{-12} \mathrm{~cm}^{2}$, respectively. The trap density of $A_{1}$ was estimated to be $\sim 2 \times 10^{14} \mathrm{~cm}^{-3}$. Actually, trap $A_{1}$ has been repeatedly observed in thin GaN layers grown by various techniques and is often associated with line defects, i.e., dislocations. ${ }^{7-10}$ This trap was also reported in AlGaN/GaN HEMTs by measuring drain leakage current at different temperatures $^{2}$ and current DLTS. ${ }^{4}$ On the other hand, trap $A_{2}$ can be induced by electron irradiation, simultaneously with another well-known trap, $E(0.16 \mathrm{eV})$. Since trap $E$ has been reliably assigned to the $\mathrm{N}$ vacancy, it seems reasonable that $A_{2}$ could be related to the $\mathrm{N}$ interstitial. ${ }^{8}$

DLTS spectra as a function of pulse length $W_{f}$, measured in the pinch-off region, are very similar for each type of SBD $(\mathrm{w} / \mathrm{o}$ and $\mathrm{w} / P$ ). Typical DLTS spectra for the SBD (w/o $P$ ) are shown in Fig. 5. From the figure and its inset, we see that trap $A_{1}$ does not show saturation as $W_{f}$ increases (even up to $300 \mathrm{~ms}$ ); in fact, for large values of $W_{f}$, it shows a logarithmic dependence. Such a dependence indicates that the trap $A_{1}$ is not related to an isolated defect, but is most likely

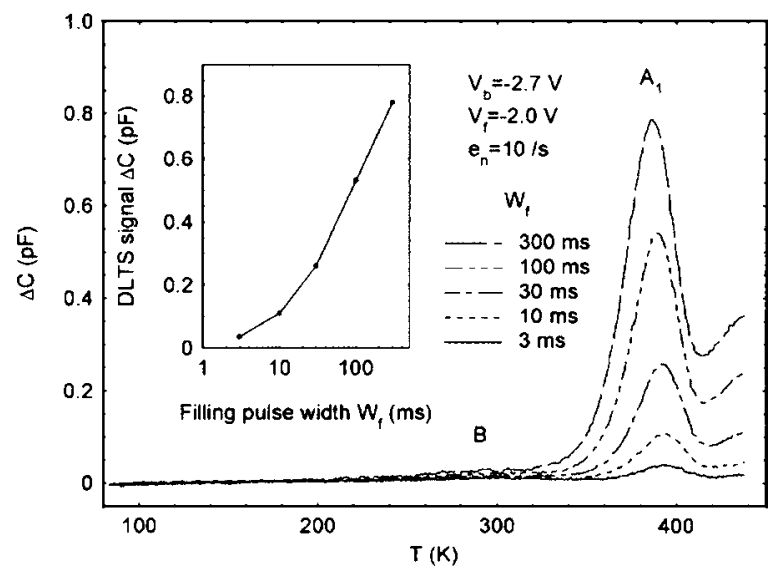

FIG. 5. DLTS spectra measured as a function of filling pulse width for the unpassivated SBD (inset shows logarithmic dependence of DLTS signal with $\left.W_{f}\right)$. 


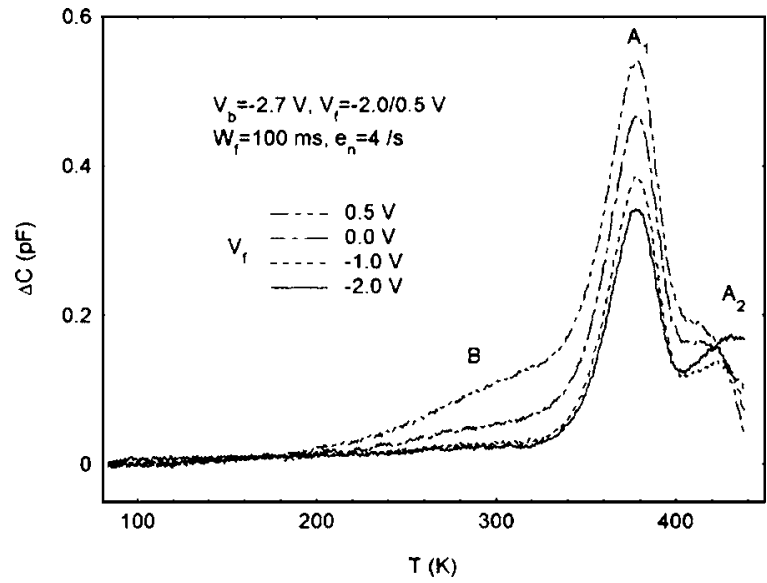

FIG. 6. DLTS spectra measured as a function of filling pulse height (across 2DEG region) for the unpassivated SBD.

associated with extended defects, such as line defects. ${ }^{10}$ The line defects here are probably due to threading dislocations in the GaN layer of the heterostructure. DLTS spectra as a function of forward-going filling pulse height $V_{f}$ for both passivated and unpassivated SBDs (not shown here) are also similar to each other in the pinch-off region. We find that the peak height of trap $A_{1}$ shows a reasonable decrease with decreasing $V_{f}$ due to reduction of the sampled volume. However, significant differences in the DLTS spectral features at high temperatures were observed when the sampling volume was varied to include the 2DEG region (by increasing $V_{f}$ from -2.0 to $0.5 \mathrm{~V}$ ), as shown in Figs. 6 and 7. For the unpassivated SBD (see Fig. 6), in addition to the dominant trap $A_{1}, A_{2}$ is observed at high temperatures in the pinch-off region $\left(V_{f}=-2.0 \mathrm{~V}\right)$. When $V_{f}$ increases from -1.0 to $0.5 \mathrm{~V}$, which corresponds to trap detection across the $2 \mathrm{DEG}$ region and near the surface of the $\mathrm{AlGaN}$ layer (see Fig. 3), $A_{1}$ keeps increasing because more sampling volume is involved, while $A_{2}$ becomes less observable. The latter phenomenon is due to the onset of negatively going DLTS signals. As compared to the case of the unpassivated SBD, the passivated SBD shows a much stronger negative signal, leading to almost no observation of $A_{2}$ in the near-surface region. Negatively going DLTS signals or hole-like traps (if negative valleys appear) have been studied for GaAs metalsemiconductor field-effect transistors and $\mathrm{AlGaAs} / \mathrm{GaAs}$ HEMTs since $1986 .{ }^{11-13}$ In these cases, there is good evidence that $\mathrm{GaAs}$ or $\mathrm{AlGaAs}$ surface states are the origin of the hole-like traps. That is, these states can trap injected electrons from the gate during the filling pulse, and produce a positive capacitance transient, ${ }^{13}$ which simulates a hole trap. To eliminate the surface states, in both GaAs and $\mathrm{GaN}$, various passivation processes have been developed. However, the passivation dielectrics are not always successful in suppressing surface related traps. For example, in a study of passivation effects on $\mathrm{AlGaN} / \mathrm{GaN}$ HEMTs by using plasma-enhanced CVD grown $\mathrm{SiO}_{2}, \mathrm{Si}_{3} \mathrm{~N}_{4}$, and $\mathrm{SiON}$, the authors found that $\mathrm{Si}_{3} \mathrm{~N}_{4}$ passivation leads to low gate leakage current, while $\mathrm{SiO}_{2}$ passivation results in an increase of gate leakage current due to the occurrence of surface related traps. ${ }^{14}$ Therefore, in this study, the observed small increases in reverse current and surface-state density after $\mathrm{Si}_{3} \mathrm{~N}_{4}$ passivation might be due to the deposition conditions used in the processing.

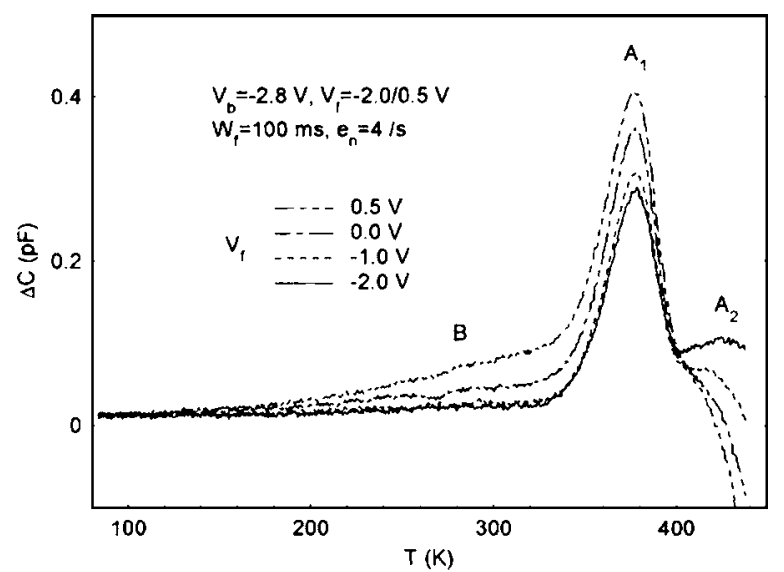

FIG. 7. DLTS spectra measured as a function of filling pulse height (across $2 \mathrm{DEG}$ region) for the passivated SBD.

In summary, AlGaN/GaN/SiC Schottky barrier diodes have been characterized by temperature-dependent $I-V, C-V$, and DLTS measurements. A dominant trap $A_{1}$ with activation energy of $1.0 \mathrm{eV}$, which is commonly observed in thin $\mathrm{GaN}$ layers grown by various techniques, has been found in the heterostructures. Based on the logarithmic dependence of the DLTS signal with filling pulse width, $\operatorname{trap} A_{1}$ is believed to be associated with threading dislocations. AlGaN surface passivation with $\mathrm{Si}_{3} \mathrm{~N}_{4}$ causes only a slight increase of reverse leakage current and pinch-off voltage. However, when the DLTS measurements sampled the region of the twodimensional electron gas, significant differences in the spectral features (i.e., observation of negatively going signals) were observed, which might be related to surface states. Further studies of hole-like traps caused by surface states in $\mathrm{AlGaN} / \mathrm{GaN}$ hetrostructures are needed.

The work of Z-Q.F. and D.C.L. was supported by AFOSR Grant No. F49620-03-1-0197 (monitored by G. Witt), ONR Grant No. N00014-03-1-0467 (C. Wood), and USAF Contract No. F33615-00-C-5402 (J. Brown).

${ }^{1}$ P. B. Klein, J. Appl. Phys. 92, 5498 (2002).

${ }^{2}$ S. Arulkumaran, T. Egawa, H. Ishikawa, and T. Jimbo, Appl. Phys. Lett. 81, 3073 (2002).

${ }^{3}$ O. Mitrofanov, M. Manfra, and N. Weimann, Appl. Phys. Lett. 82, 4361 (2002).

${ }^{4}$ A. P. Zhang, L. B. Rowland, E. B. Kaminsky, V. Tilak, J. C. Grande, J. Teetsov, A. Vertiatchikh, and L. F. Eastman, J. Electron. Mater. 32, 388 (2003).

${ }^{5}$ T. Hashizume, J. Kotani, and H. Hasegawa, Appl. Phys. Lett. 84, 4884 (2004).

${ }^{6}$ E. J. Miller, E. T. Yu, P. Waltereit, and J. S. Speck, Appl. Phys. Lett. 84, 535 (2004).

${ }^{7}$ Z.-Q. Fang, D. C. Look, J. Jasinski, M. Benamara, Z. Liliental-Weber, and R. J. Molnar, Appl. Phys. Lett. 78, 332 (2001).

${ }^{8}$ Z.-Q. Fang, L. Polenta, J. W. Hemsky, and D. C. Look, in Proceedings of the International Semiconducting and Insulating Materials Conf. (Canberra), edited by C. Jagadish and N. J. Welham (IEEE, Piscataway, NJ, 2000), p. 35.

${ }^{9}$ A. Hierro, A. R. Arehart, B. Heying, M. Hansen, J. S. Speck, U. K. Mishra, S. P. DenBaars, and S. A. Ringel, Phys. Status Solidi B 228, 309 (2001).

${ }^{10}$ Z.-Q. Fang, D. C. Look, and P. Polenta, J. Phys.: Condens. Matter 14, 13061 (2002).

${ }^{11}$ S. R. Blight, R. H. Wallis, and H. Thomas, IEEE Trans. Electron Devices ED-33, 1447 (1986).

${ }^{12}$ J. H. Zhao, IEEE Trans. Electron Devices ED-37, 1235 (1990).

${ }^{13}$ K. J. Choi and J.-L. Lee, J. Vac. Sci. Technol. B 19, 615 (2001).

${ }^{14}$ S. Arulkumaran, T. Egawa, H. Ishikawa, T. Jimbo, and Y. Sano, Appl. Phys. Lett. 84, 613 (2004). 